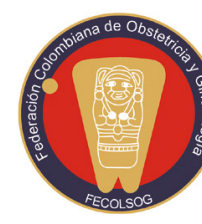

\title{
LA REVISTA COLOMBIANA DE OBSTETRICIA Y GINECOLOGÍA Y SU NUEVO PROCESO EDITORIAL
}

omo mencionamos en el editorial del número anterior, la Revista Colombiana de Obstetricia y Ginecología (RCOG) ha sido aceptada nuevamente en la base de datos Medline a partir de este año. Esta aceptación coincidió con un cambio de nuestro equipo editorial, a partir del presente número el proceso de gestión editorial será acompañado por Biteca S.A.S, empresa especialista en el campo y con amplia trayectoria en acompañamiento de procesos de gestión editorial para revistas científicas.

Lamentamos los inconvenientes que este cambio haya podido causar, pero el mismo ha significado el rediseño de los procesos editoriales, desde la revisión de las listas de chequeo a fin de que los manuscritos sean aceptados para iniciar el proceso de evaluación por pares, hasta la verificación final de los documentos en su forma final de publicación.

Estos cambios significan un mayor compromiso tanto del equipo editorial como de los autores. Es importante que estos últimos conozcan los pasos y tiempos que debemos cumplir para tener un proceso editorial ágil y de alta calidad

Estos son:

a) No serán admitidos documentos que no cumplan con todos y cada uno de los requisitos descritos en la lista de chequeo de aceptación de manuscritos. Por tanto, se solicita a los autores verificar en detalle estos criterios, que fueron modificados recientemente y se encuentran disponibles en la página de la $\mathrm{RCOG}^{1}$.

\footnotetext{
https://revista.fecolsog.org/index.php/rcog/about/submissions
}

b) Una vez verificado el cumplimiento de la lista de chequeo, el estudio será evaluado por un miembro del comité editorial que definirá si este se encuentra dentro de los temas que hacen parte del alcance de la revista, y si su contenido es relevante para los lectores de la RCOG. El alcance de la RCOG se encuentra en la página de presentación de la Revista².

c) Posteriormente, los documentos que cumplan con los dos requisitos previos serán enviados a evaluación por dos o tres pares en un proceso independiente y enmascarado respecto a la identificación de los autores. Con esto se busca reducir el riesgo de sesgos de selección. Estos pasos serán llevados a cabo en los primeros 15 días de enviado el manuscrito.

d) El proceso de revisión por pares tomará máximo 30 días, periodo en el que se estará enviando la decisión de los pares a los autores y los comentarios de estos en caso de que el estudio sea considerado como "aceptado, aceptado con cambios menores o aceptable con modificaciones mayores para publicación”. En caso de no ser aceptado se enviarán las razones de esta decisión.

e) Se dará un plazo de 30 días a los autores para contestar los comentarios de los pares y hacer los cambios sugeridos, considerados como relevantes y pertinentes. La respuesta se deberá enviar en una carta aparte en la que respondan cada uno de los comentarios de los pares de manera específica, si estos son aceptados, y, en caso de no aceptarlos,

https://revista.fecolsog.org/index.php/rcog/about 
explicando la razón por la cual no están de acuerdo. Además, deben describir el cambio incluido y el sitio donde se incluyó, resaltado en amarillo para su fácil identificación por los pares.

f) En los siguientes 15 días el equipo editorial enviará la respuesta a los autores sobre si el documento puede seguir el proceso editorial, y, en caso de ser así, si se requieren nuevos cambios.

g) Si se requieren nuevos cambios los autores tendrán 8 días para hacerlos. Los autores enviarán una nueva carta en la que expliquen las modificaciones realizadas y, en caso de no estar de acuerdo, las razones que justifiquen su decisión.

h) Una vez aceptado, el documento será enviado a corrección de estilo y en los siguientes 15 días será nuevamente remitido al autor para verificar que está de acuerdo con los cambios en este paso. Esta respuesta no debe durar más de 5 días.

i) Posteriormente, la versión será enviada a diagramación y el PDF diagramado del manuscrito será remitido en los siguientes 5 días al autor responsable de la correspondencia para verificar que el manuscrito está debidamente diagramado y el contenido es fiel al documento en versión de Word. La aceptación de los autores debe llegar en los 5 días siguientes.

j) Posteriormente, el estudio será publicado en la revista.

Este proceso debe llevar un tiempo de 3 a 4 meses en total, desde la aceptación del estudio hasta su publicación. Ya se inició con la aplicación de la lista de chequeo a los documentos enviados desde marzo de este año.

Creemos que nuestros autores, que ya producen investigación de alta calidad, deben ser competentes en el cumplimiento de los estándares internacionales de publicación de revistas de alta circulación e impacto, y contamos con su compromiso, así como con el del equipo editorial que seguirá apoyándolos para que los manuscritos publicados en la RCOG sigan siendo de una gran calidad científica y editorial.

Cordialmente,

Hernando Gaitán Duarte, MD, MSc Editor 